\title{
Characterization of hard scale formed in the kraft mill green liquor processing equipment
}

TASNUVA ZAKIR, HONGHI TRAN, AND VLADIMIROS G. PAPANGELAKIS

\begin{abstract}
Scaling, the formation of hard deposits, in green liquor handling systems is a persistent problem in many kraft pulp mills. Scaling is commonly believed to be a result of pirssonite $\left(\mathrm{Na}_{2} \mathrm{CO}_{3} \cdot \mathrm{CaCO}_{3} \cdot 2 \mathrm{H}_{2} \mathrm{O}\right)$ formation when the green liquor total titrateable alkali (TTA) is high. In this study, we characterized 12 scale samples obtained from 10 kraft pulp mills using various analytical methods, including TGA/DSC (thermogravimetric analysis/ differential scanning calorimetry), XRF (X-ray fluorescence spectrometry), XRD (X-ray diffraction spectrometry), SEM (scanning electron microscopy), and EMPA (electron microprobe analyzer). The analysis identified only four of these samples as pirssonite; the remaining consisted mostly of calcite $\left(\mathrm{CaCO}_{3}\right)$. The reason for the predominant presence of calcite in the majority of the scale samples is not known. It may be a result of selective dissolution of sodium carbonate $\left(\mathrm{Na}_{2} \mathrm{CO}_{3}\right)$ from the pirssonite scale during the time when the green liquor total TTA was low, leaving the insoluble $\mathrm{CaCO}_{3}$ behind.

Application: Characterization of hard deposits formed in green liquor handling systems is vital in determining what scales are and how they form. This is a necessary step toward developing a viable means for minimizing the scaling problem.
\end{abstract}

n kraft pulp mills, molten smelt from the recovery boiler is dissolved with weak wash in the dissolving tank to produce green liquor, which is transported through pipelines to green liquor storage tanks, clarifiers, slakers, and causticizers. Scale, or deposit material, often forms on the dissolving tank wall, floor, agitator shaft and blades; on the internal walls of pipelines and pumps; and to a lesser extent, in the liquor storage tanks and clarifiers. Figure 1 shows an example of scaling in a pipeline. The scale is hard, stratified with black and gray layers, and clogs up $85 \%$ of the crosssection opening of the pipe.

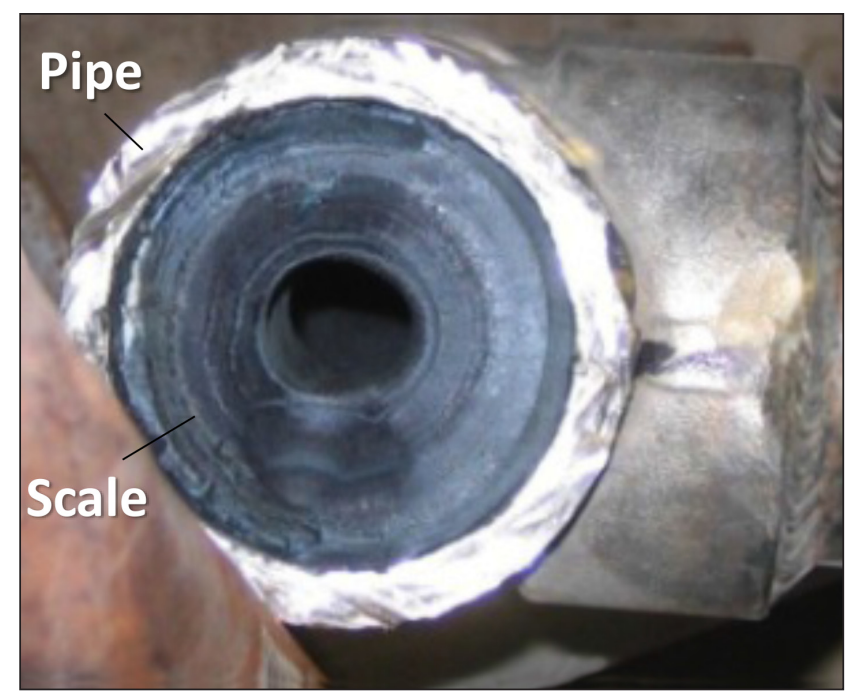

1. Hard scale formed in a green liquor pipeline.
Scaling hinders mixing in the dissolving tank and restricts the liquor flow through the pipeline and pumps. In severe cases, scaling leads to unscheduled shutdowns for deposit removal. Scaling experience varies from mill to mill. Frederick et al. [1] discussed green liquor scale problems at the Weyerhaeuser Springfield (Oregon) mill, where 6 -in. (15-cm) valve openings in the raw green liquor pipelines were reduced to only $1 \mathrm{in}$. (2.5 cm). Kosonen and Salmenoja [2] reported that at a mill in Imatra, Finland, the scale that grew on the dissolving tank impeller blades was so massive that the agitator motors exceeded the amperage limits and had to be stopped for scale removal in less than 3 months. This inevitably led to unscheduled shutdowns of the recovery boiler, resulting in substantial production losses.

Green liquor scale is believed to be composed of pirssonite, a double salt of sodium carbonate and calcium carbonate with a chemical formula of $\mathrm{Na}_{2} \mathrm{CO}_{3} \cdot \mathrm{CaCO}_{3} \cdot 2 \mathrm{H}_{2} \mathrm{O}$ or $\mathrm{Na}_{2} \mathrm{Ca}\left(\mathrm{CO}_{3}\right)_{2} \cdot 2 \mathrm{H}_{2} \mathrm{O}[1-3]$. While pirssonite has often been cited in the literature to be the major component of green liquor scale, only a few papers have provided evidence of its presence. Frederick et al. [1] discussed pirssonite deposition problems in great detail, but did not mention the deposit composition. Taylor and McGuffie [4] found both calcite and pirssonite in the green liquor scale samples that they collected at the Elk Falls mill in British Columbia. They reported that the deposit sample collected from the dissolving tank primarily was composed of pirssonite $(91.6 \mathrm{wt} \%$ ) while the sample obtained from the green liquor clarifier line mainly consisted of calcite (85.1 wt\%). Martins et al. [5] reported the presence of pirssonite along with calcite $\left(\mathrm{CaCO}_{3}\right)$, portlandite 
$\left(\mathrm{Ca}[\mathrm{OH}]_{2}\right)$, larnite $\left(\mathrm{Ca}_{2} \mathrm{SiO}_{4}\right)$, and brucite $\left(\mathrm{Mg}[\mathrm{OH}]_{2}\right)$ in the slaker grit sample obtained from a kraft mill in Brazil.

The composition of green liquor scale must have been known at individual mills, particularly those that experienced severe scaling problems. However, from the published literature information, it is unclear whether the scale consisted of mainly pirssonite, or of a mixture of pirssonite, $\mathrm{CaCO}_{3}$ and other compounds that are typically found in grits, dregs, and lime mud.

A systematic study was, therefore, undertaken to examine what the green liquor scale consists of, how it forms and becomes hard, and how the scaling process is affected by dissolving tank/recausticizing plant operating variables (e.g., temperature, total titratable alkali [TTA], sulfidity). Another objective was to develop viable means for minimizing the scaling problem. The study consisted of three parts: (1) characterizing scale samples obtained from various kraft pulp mills; (2) investigating conditions under which pirssonite may precipitate from the solution; and (3) obtaining the thermodynamic data for pirssonite formation and incorporating the data into a commercially available thermodynamic program, OLI, to predict conditions leading to scale formation.

This paper discusses the experimental procedures used in and the results obtained from Part 1 of the study.

\section{EXPERIMENTAL PROCEDURES}

A total of 12 scale samples obtained from 10 different kraft pulp mills in Canada, United States, Brazil, and New Zealand were characterized. A small amount (about $5 \mathrm{~g}$ ) was chiseled out from each scale sample, dried at $110^{\circ} \mathrm{C}$ for $6 \mathrm{~h}$, ground into fine powder, and kept in a sealed glass container until it was subjected to analysis. The analysis was performed using a simultaneous thermogravimetric analysis/differential scanning calorimetry (TGA/DSC) analyzer. Selected samples were further analyzed using X-ray fluorescence (XRF), X-ray powder diffraction (XRD) spectrometers, an electron microprobe analyzer (EMPA), and scanning electron microscopy (SEM) to confirm the results obtained with TGA/DSC.

In TGA/DSC experiments, the sample was heated up to $1000^{\circ} \mathrm{C}$ in nitrogen $\left(\mathrm{N}_{2}\right)$ at a heating rate of $20^{\circ} \mathrm{C} / \mathrm{min}$. Changes in sample weight and thermal events that occurred during heating were continuously monitored. The TGA/DSC thermal profile for each sample was compared against the thermal profiles for two standard chemicals: the analytical grade $\mathrm{CaCO}_{3}$ from Fisher Scientific (Pittsburgh, PA, USA) and the pirssonite crystal from Mineralogical Research Company (San Jose, CA, USA).

\section{RESULTS AND DISCUSSION}

\section{Thermal profile for $\mathrm{CaCO}_{3}$}

As shown in Fig. 2, the thermal profile of the standard $\mathrm{CaCO}_{3}$ consists of a single endothermic peak, corresponding to the decomposition of $\mathrm{CaCO}_{3}$ into $\mathrm{CaO}$ and $\mathrm{CO}_{2}$. This decomposition occurs in $\mathrm{N}_{2}$ between $600^{\circ} \mathrm{C}$ and $830^{\circ} \mathrm{C}$. The weight loss resulting from $\mathrm{CO}_{2}$ escaping from the sample is about $43 \mathrm{wt} \%$,

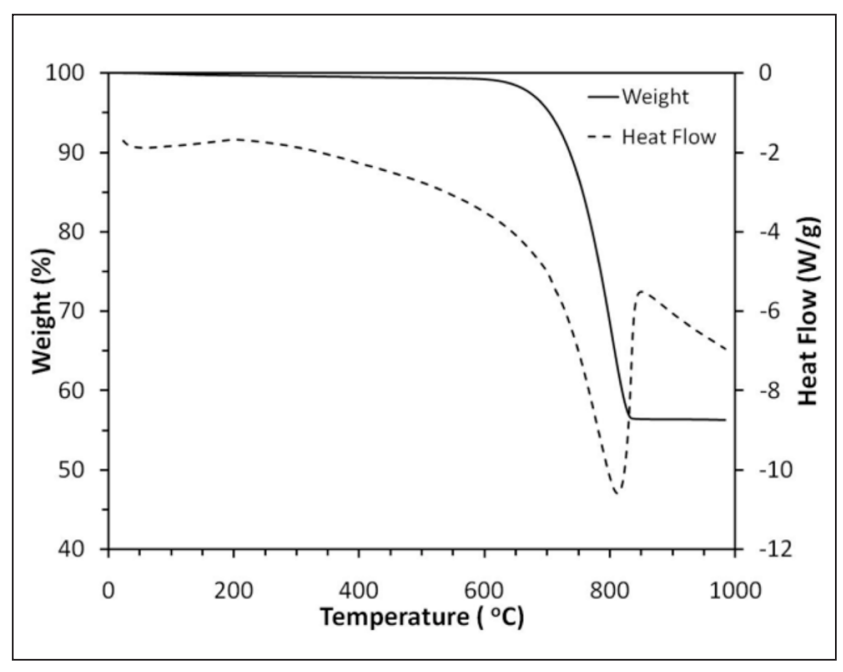

2. Thermogravimetric analysis/differential scanning calorimetry (TGA/DSC) thermal profile for the pure calcite used as standard.

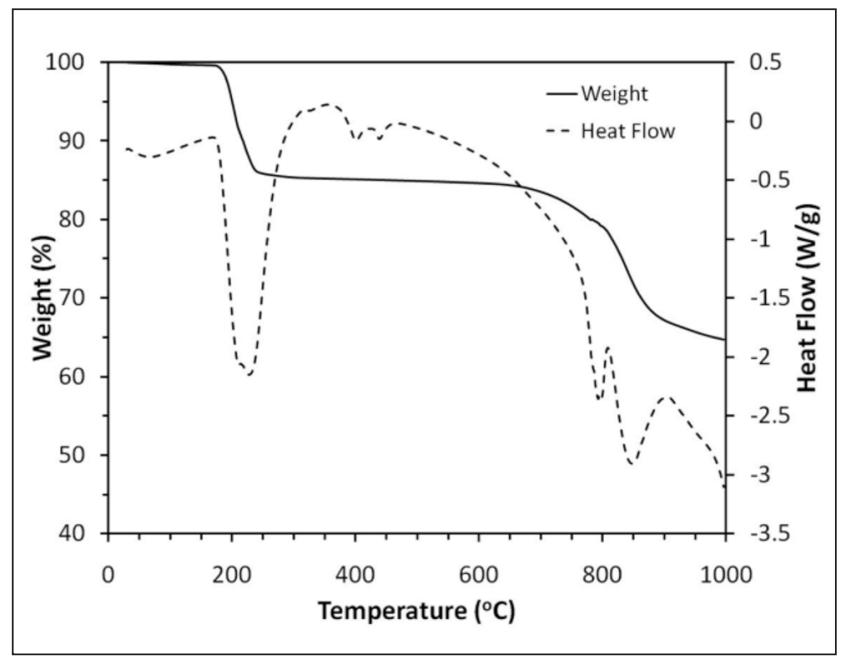

3. TGA/DSC thermal profile for the commercial pirssonite crystal used as standard.

which is close to $44 \mathrm{wt} \%$-the theoretical weight loss of $\mathrm{CaCO}_{3}$.

\section{Thermal profile for pirssonite}

The thermal profile of the standard pirssonite is shown in Fig. 3. It consisted of four main events: (1) the dehydration of pirssonite between $150^{\circ} \mathrm{C}$ and $230^{\circ} \mathrm{C}$ that resulted in a $15 \%$ weight loss of the sample, (2) two solid-solid phase transitions of anhydrous $\mathrm{Na}_{2} \mathrm{Ca}\left(\mathrm{CO}_{3}\right)_{2}$ at $360^{\circ} \mathrm{C}$ and $430^{\circ} \mathrm{C}$, (3) the decomposition of $\mathrm{CaCO}_{3}$ into $\mathrm{CaO}$ and $\mathrm{CO}_{2}$ between $670^{\circ} \mathrm{C}$ and $870^{\circ} \mathrm{C}$ that resulted in an additional $18 \%$ weight loss, and (4) the melting of the $\mathrm{Na}_{2} \mathrm{CO}_{3}$ at around $850^{\circ} \mathrm{C}$ with no weight loss. There was a slight overlap between events 3 and 4 .

The approximate weight changes and chemical reactions involved in the above four steps are summarized in Table $\mathbf{I}$. The profile obtained in this study was similar to that of pirssonite obtained by Ulmgren et al [6]. 


\begin{tabular}{|l|l|l|l|}
\hline $\begin{array}{l}\text { Temperature } \\
\text { Range }\end{array}$ & \multicolumn{1}{|c|}{ Steps } & \multicolumn{1}{c|}{$\begin{array}{c}\text { Reactions } \\
\text { Change }\end{array}$} \\
\hline $150^{\circ} \mathrm{C}-230^{\circ} \mathrm{C}$ & Dehydration & $\mathrm{Na}_{2} \mathrm{CO}_{3} \cdot \mathrm{CaCO}_{3} \cdot 2 \mathrm{H}_{2} \mathrm{O} \rightarrow \mathrm{Na}_{2} \mathrm{CO}_{3} \cdot \mathrm{CaCO}_{3}$ & $15 \%$ loss \\
\hline $360^{\circ} \mathrm{C}$ and $430^{\circ} \mathrm{C}$ & Solid-solid phase transitions & From one form of $\mathrm{Na}_{2} \mathrm{CO}_{3} \cdot \mathrm{CaCO}_{3}$ to another & No change \\
\hline $670^{\circ} \mathrm{C}-870^{\circ} \mathrm{C}$ & $\begin{array}{l}\text { Decomposition of } \mathrm{CaCO}_{3} \text { in anhy- } \\
\text { drous pirssonite }\end{array}$ & $\mathrm{Na}_{2} \mathrm{CO}_{3} \cdot \mathrm{CaCO}_{3}(\mathrm{~s}) \rightarrow \mathrm{Na}_{2} \mathrm{CO}_{3}+\mathrm{CaO}+\mathrm{CO}_{2}$ & $18 \%$ loss \\
\hline $850^{\circ} \mathrm{C}$ & Melting of $\mathrm{Na}_{2} \mathrm{CO}_{3}$ & $\mathrm{Na}_{2} \mathrm{CO}_{3}(\mathrm{~s}) \rightarrow \mathrm{Na}_{2} \mathrm{CO}_{3}(\mathrm{I})$ & $\mathrm{No} \mathrm{change}$ \\
\hline
\end{tabular}

\section{Thermal events and reactions occurring during the heating of pirssonite.}

\section{Scale characterization}

Figure 4 shows photos of the 12 scale samples characterized in this study. The letter and the Roman numeral below each photo represent the mill and sample identifications. Six of the scale samples (i.e., A, C-II, D, E, F, and G) were collected from the pipeline after the dissolving tank. Sample C-I was taken from the slaker. Sample H-I was collected from the feed tube of the centrifuge that takes the underflow of the clarifier, and sample H-II was obtained from the dissolving tank agitator blade. Sample I was taken from the pump after the green liquor cooler, and sample J was collected from the valve of the pipeline that carries green liquor from the clarifier to the slaker. The extract location of sample B is not known.

From their TGA/DSC thermal profiles and elemental analysis results, four of these samples were identified as pirssonite (samples C-I, H-II, I, and J). The other eight consisted mostly of calcite and no pirssonite. Sample F, however, also contained calcite but was mixed with some calcium sulfate $\left(\mathrm{CaSO}_{4}\right)$ and manganese oxide (MnO). Three (C-I, I, and J) of the four samples identified as pirssonite appeared to contain large, glassy crystals (Fig. 5a) and were relatively brittle. The fourth sample (H-II) was densely packed and did not contain large crystals; however, a closer look revealed its shiny surface containing very small crystals (Fig. 5b).

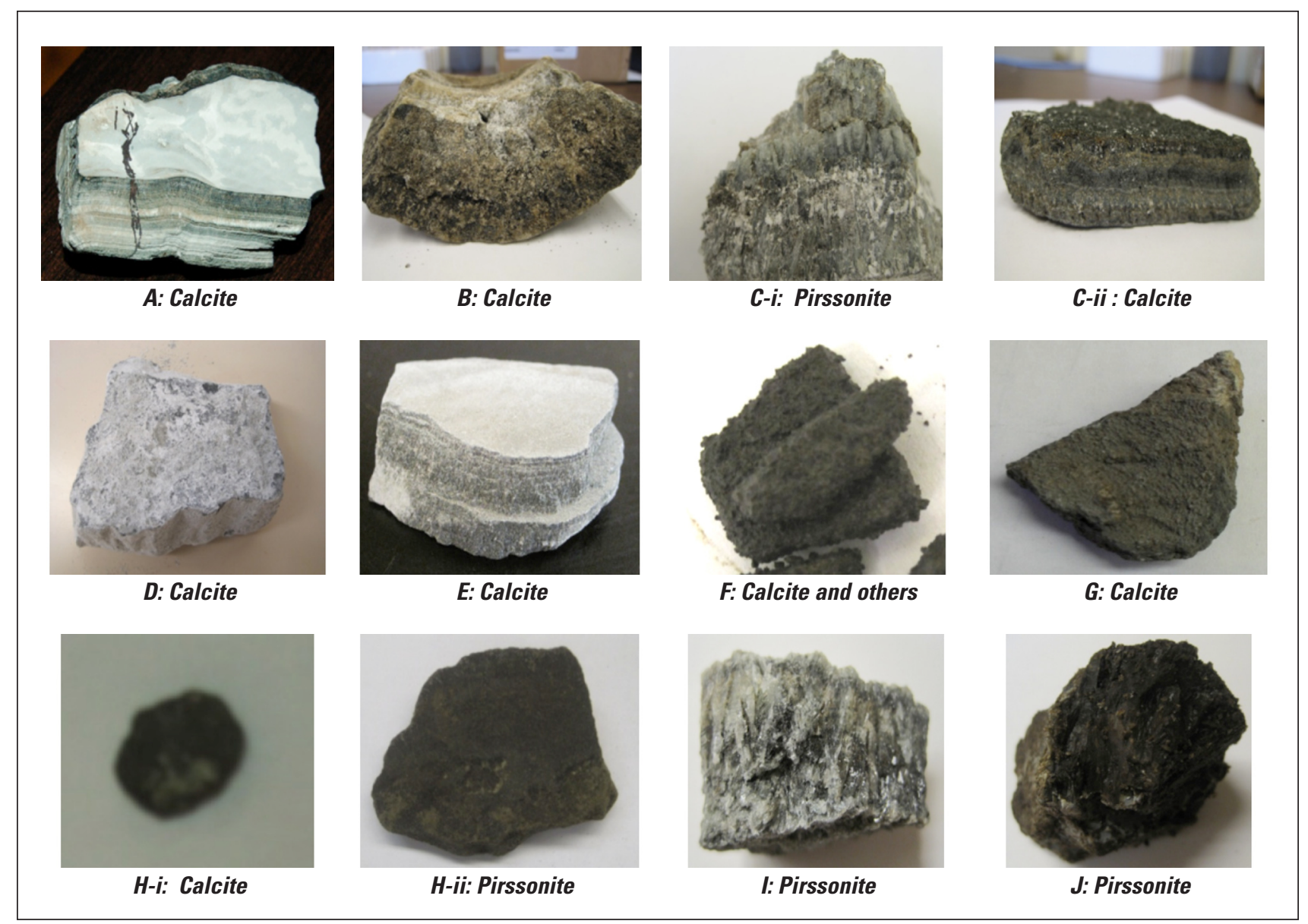

4. Green liquor scale samples obtained from various kraft pulp mills. 


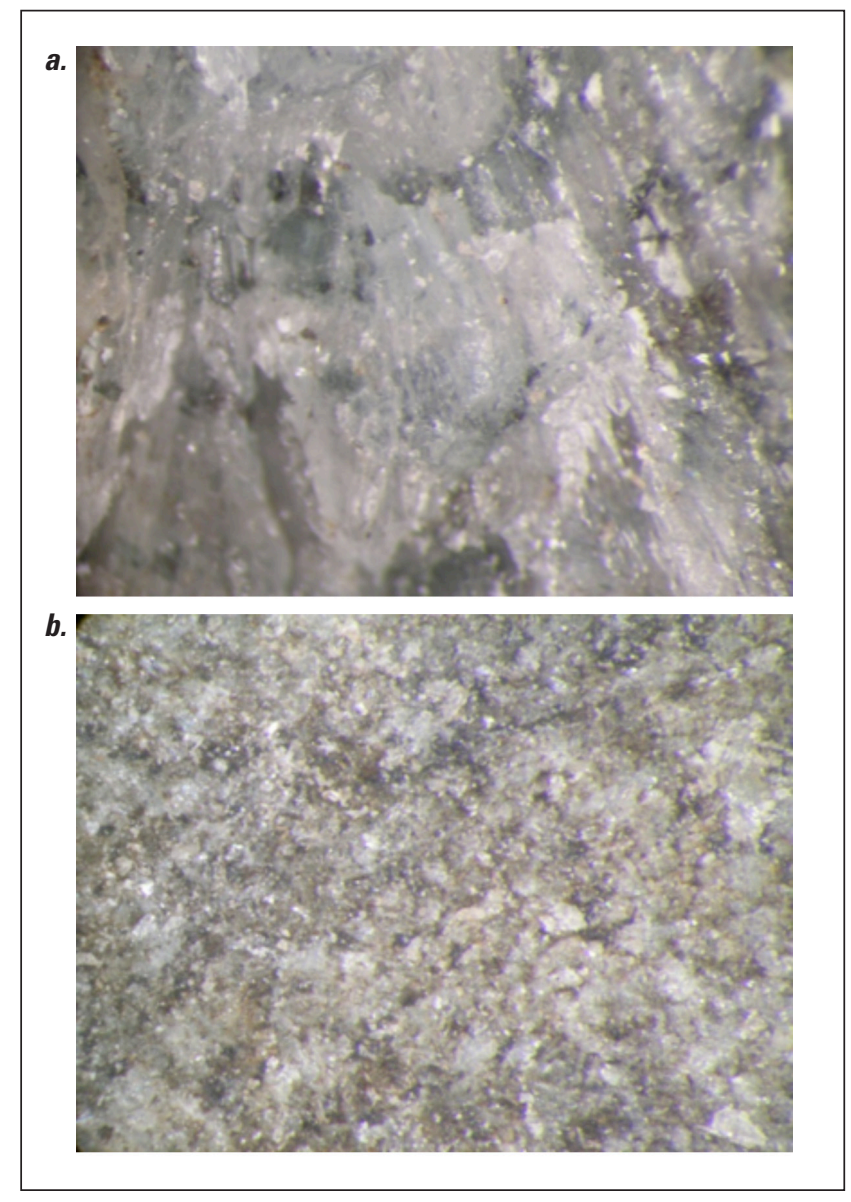

\section{Pirssonite scale samples observed at x450 magnification using an optical microscope.}

Samples identified as calcite were harder and contained many layers (e.g., sample A in Fig. 4). Despite its stratified appearance, sample A had a relatively uniform composition, which was verified by scanning the cross-section of the sample using EMPA. Figure $\mathbf{6}$ shows the cross-section of sample A embedded in an epoxy mount that was used in EMPA. The white arrow indicates the direction of scan performed on this sample. Figure 7 shows the elemental scan obtained for the scale sample across its $1.4-\mathrm{cm}$ cross-section. The large amount of calcium (about $41 \mathrm{wt} \%$ ) and a very small amount of sodium $(0.15 \mathrm{wt} \%)$ in the sample indicate that the sample contained mostly $\mathrm{CaCO}_{3}$ along with some other calcium compounds.

Two examples were representative of how TGA/DSC thermal profiles were used to characterize the scale samples in this study. Figure 8 shows sample A (calcite) and Fig. 9 shows sample I (pirssonite).

The thermal profiles for sample A in Fig. 8 were strikingly similar to those for pure $\mathrm{CaCO}_{3}$ (seen in Fig. 2). The major endothermic peak was observed between $620^{\circ} \mathrm{C}$ and $830^{\circ} \mathrm{C}$, which is characteristic of $\mathrm{CaCO}_{3}$. The weight loss associated with this peak was about $42 \%$, indicating the $\mathrm{CaCO}_{3}$ content in sample A was about 95\%. In Fig. 9, the first four endothermic peaks summarized in Table I are clearly visible. The first

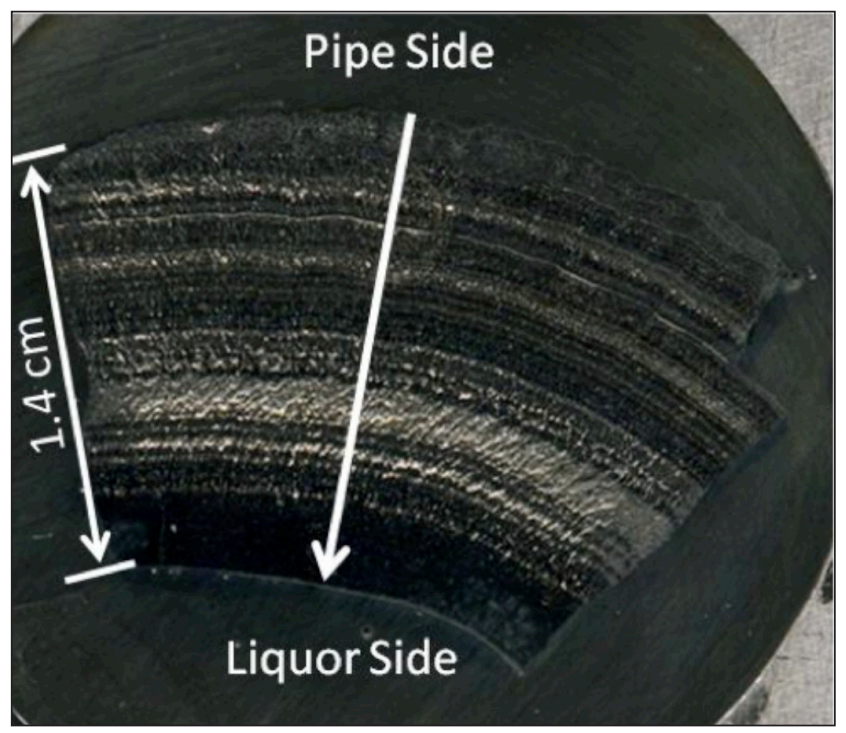

\section{Cross-section of sample A used in electron microprobe analyzer (EMPA).}

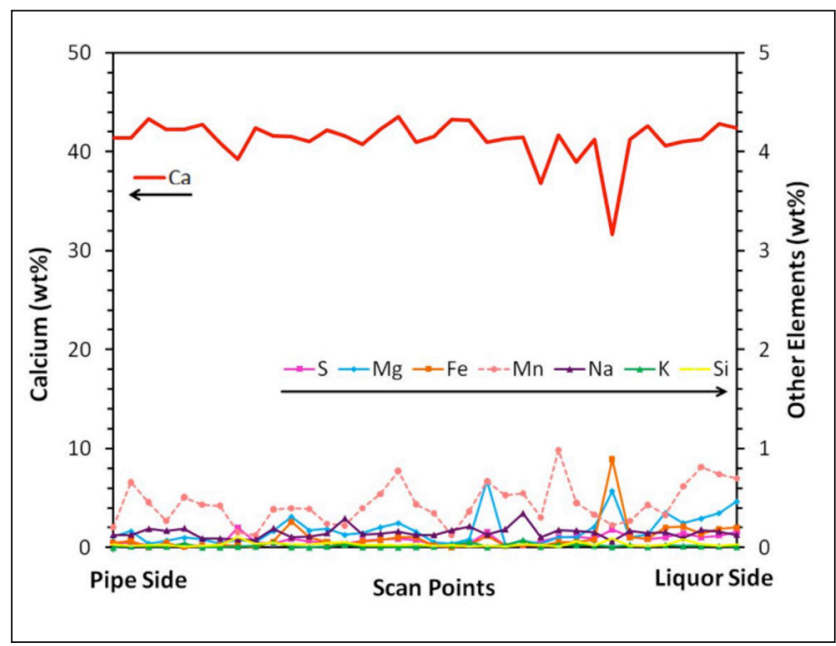

7. Analysis by EMPA across scale sample $A$.

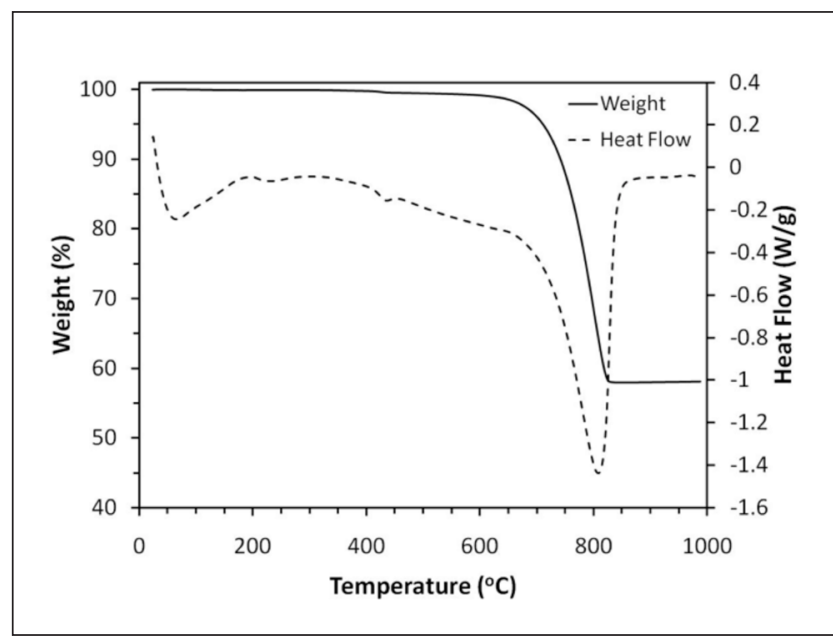

8. TGA/DSC thermal profile for sample $A$. 


\begin{tabular}{|l|c|c|}
\hline Elements (XRF) & Sample A & Sample I \\
\hline $\mathrm{Ca}$ & 38.3 & 16.0 \\
\hline $\mathrm{Na}$ & 0.73 & 18.7 \\
\hline $\mathrm{Mg}$ & 0.57 & 0.16 \\
\hline $\mathrm{S}$ & 0.23 & 0.28 \\
\hline $\mathrm{Mn}$ & 0.44 & 0.05 \\
\hline $\mathrm{Fe}$ & 0.25 & 0.03 \\
\hline $\mathrm{Al}$ & 0.07 & 0.03 \\
\hline $\mathrm{Si}$ & 0.09 & 0.04 \\
\hline $\mathrm{P}$ & 0.04 & Trace \\
\hline $\mathrm{K}$ & 0.01 & 0.02 \\
\hline $\mathrm{Sr}$ & Trace & 0.34 \\
\hline $\mathrm{Ba}$ & 0.22 & Trace \\
\hline Other (e.g., $\mathrm{Ni}, \mathrm{Zn}, \mathrm{Cu}, \mathrm{Cl})$ & 0.13 & 0.03 \\
\hline
\end{tabular}

\section{Composition of sample A and sample I (wt\%).}

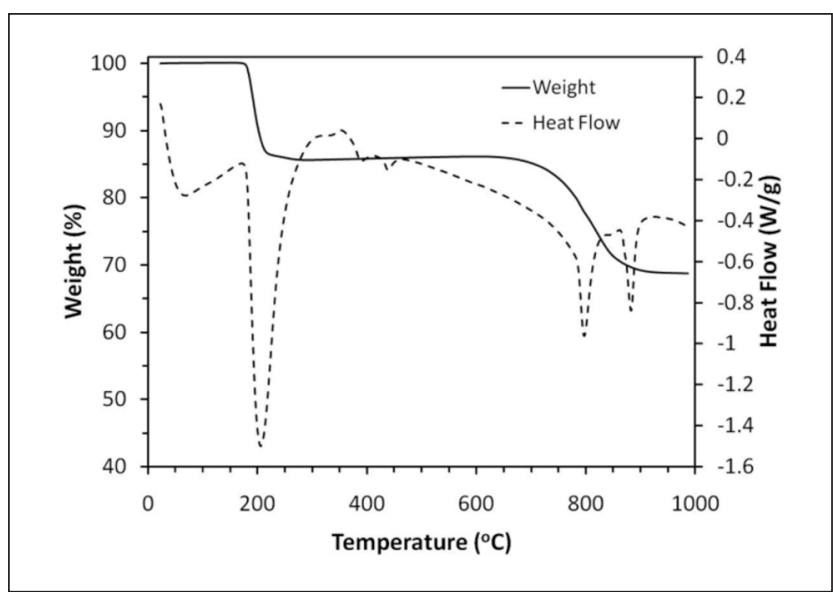

\section{TGA/DSC thermal profile for sample I.}

weight loss associated with the dehydration of water was about $15 \%$ and the second weight loss associated with the decomposition of $\mathrm{CaCO}_{3}$ was about $17 \%$. A complete decomposition of $\mathrm{CaCO}_{3}$ from pure pirssonite would have a weight loss of $18 \%$; therefore, it could be concluded that sample I consisted mostly of pirssonite (at least 95\%), with some other minor impurities.

Table II summarizes elemental compositions of samples A and I determined by XRF. Sample A contained $38.3 \mathrm{wt} \%$ calcium (or $96 \mathrm{wt} \% \mathrm{CaCO}_{3}$ ) with little sodium. Sample I, on the other hand, contained less calcium but a much larger amount of sodium. The $\mathrm{Na}_{2} / \mathrm{Ca}$ molar ratio for this sample was $(18.7 / 46) /(16 / 40)=1.0$, indicative of pirssonite. These results were consistent with TGA/DSC results, suggesting that sample A consisted of mostly $\mathrm{CaCO}_{3}$ and sample I of mostly pirssonite.

Note that the potassium-to-sodium plus potassium molar ratio, $\mathrm{K} /(\mathrm{Na}+\mathrm{K})$ in green liquor varies between $5 \mathrm{~mol} \%$ and $10 \mathrm{~mol} \%$. If a double salt containing potassium, such as $\mathrm{K}_{2} \mathrm{CO}_{3} \cdot \mathrm{CaCO}_{3}$ or $\mathrm{Na}_{2} \mathrm{CO}_{3} \cdot \mathrm{K}_{2} \mathrm{CO}_{3} \cdot \mathrm{nH}_{2} \mathrm{O}$ is also precipitated along with pirssonite, the potassium concentration in the

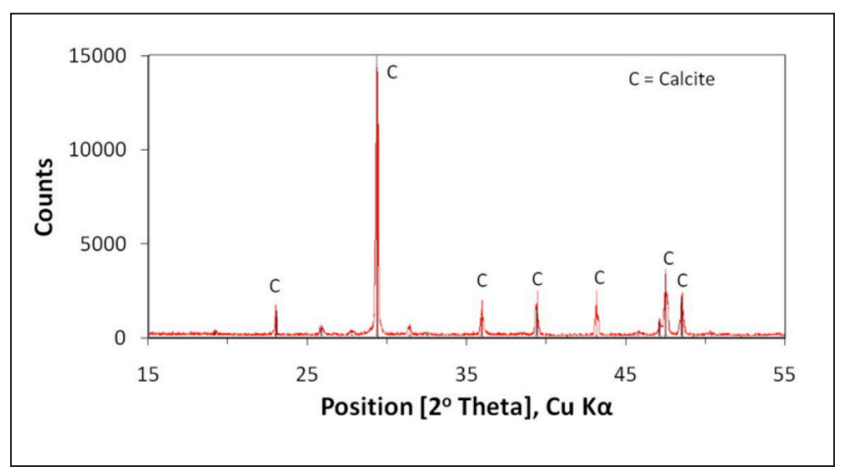

10. X-ray powder diffraction result for sample $A$ (calcite).

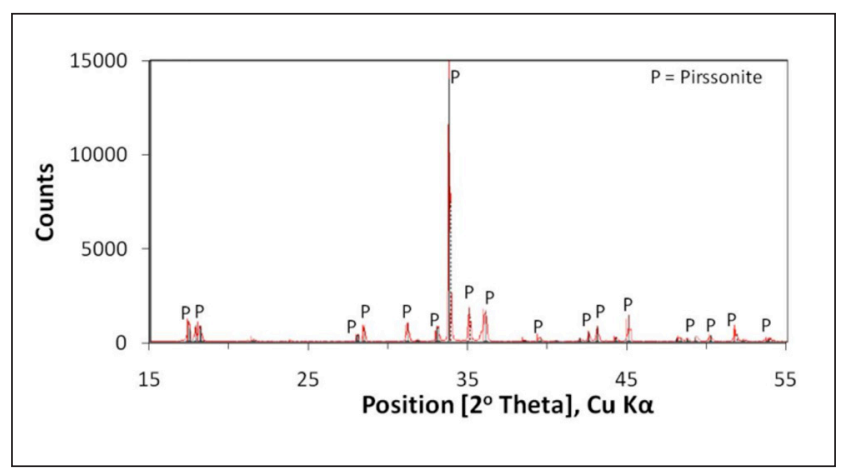

11. X-ray powder diffraction result for sample I (pirssonite).

solid phase should be substantially higher. As shown in Table II, however, the potassium concentration in sample I was very small, $0.02 \mathrm{wt} \%$, consistent with that in another pirssonite scale (Sample C-I), $<0.04 \mathrm{wt} \%$. These results suggested that potassium compounds do not coprecipitate with pirssonite and hence, do not take part in scale formation.

X-ray diffraction analysis was also used to confirm the mineral phases present in sample A and sample I. In Fig. 10 and Fig. 11, the XRD patterns for these two samples show the dominance of calcite in sample A and pirssonite in sample I.

Figure 12 shows the SEM images obtained for sample A and sample I. The size of the calcite grains are approximately $1 \mu \mathrm{m}$, with smooth intergrown blocks. The grains for pirssonite are much larger, ranging from about $100 \mu \mathrm{m}$ to $300 \mu \mathrm{m}$. The orthorhombic crystal structure observed in sample I is characteristic of pirssonite crystal structure, as reported in the literature [7].

\section{IMPLICATIONS}

Scaling in a pipeline occurs when crystals of a compound precipitate from the liquid that flows through the pipeline; the crystals are a result of supersaturation of that compound in the liquid. The three compounds that form pirssonite in the green liquor handling systems are $\mathrm{Na}_{2} \mathrm{CO}_{3}, \mathrm{CaCO}_{3}$ and water $\left(\mathrm{H}_{2} \mathrm{O}\right)$. Because $\mathrm{Na}_{2} \mathrm{CO}_{3}$ and $\mathrm{H}_{2} \mathrm{O}$ are the main components of the green liquor, they are inherently present; $\mathrm{CaCO}_{3}$ originates from calcium compounds in smelt and/or from lime mud particles suspended in the weak wash.

Because $\mathrm{Na}_{2} \mathrm{CO}_{3}$ is highly soluble in green liquor and JANUARY 2013 | VOL. 12 N0. 1 | TAPPI JOURNAL 59 


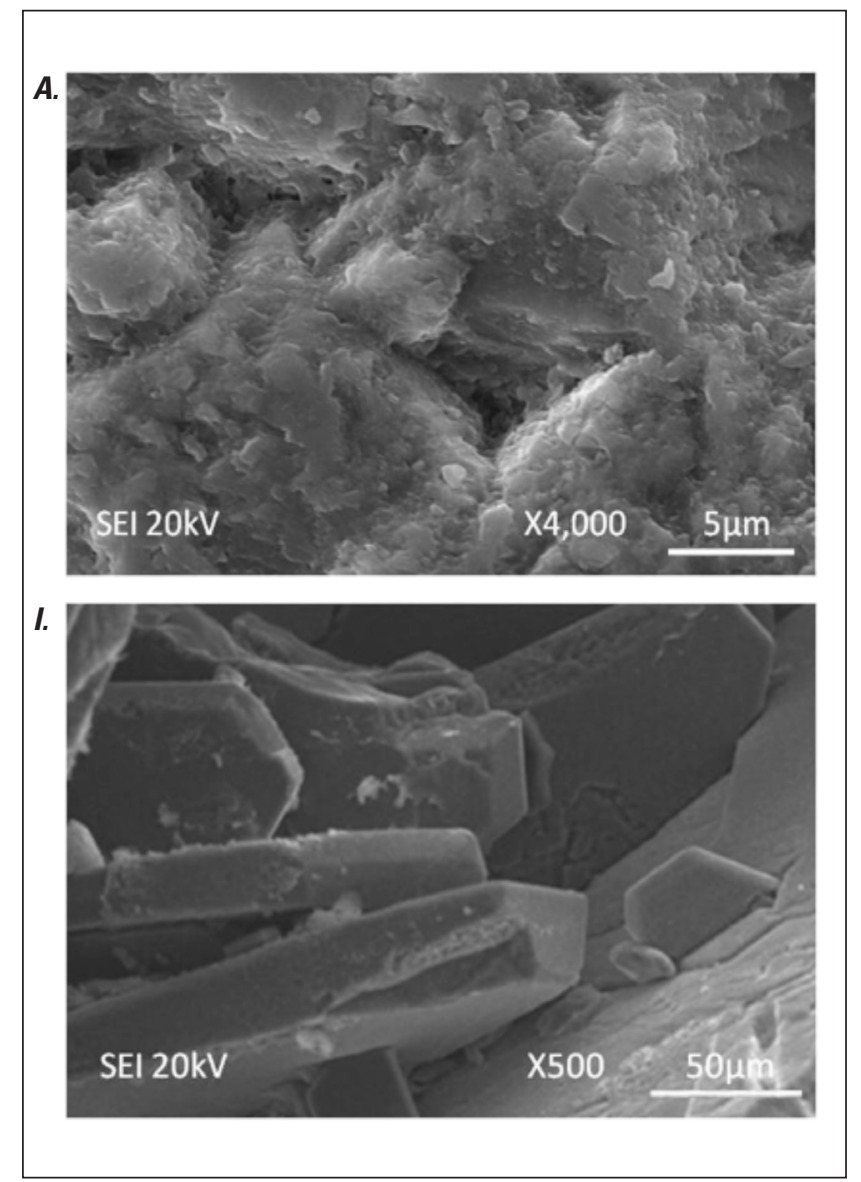

12. Micrographs from scanning electron microscopy (SEM) of sample $A$ and sample $I$.
$\mathrm{CaCO}_{3}$ has very low solubility, pirssonite may form through one of the following mechanisms: (1) direct reaction between $\mathrm{Na}_{2} \mathrm{CO}_{3}$ in the solution and the surface of $\mathrm{CaCO}_{3}$ particles or (2) continuous dissolution of $\mathrm{CaCO}_{3}$ particles to sustain the amounts of free $\mathrm{Ca}^{2+}$ ions in the solution that subsequently react with the $\mathrm{Na}^{+}$and $\mathrm{CO}_{3}{ }^{2-}$ ions to precipitate pirssonite as a new phase. The transformation of calcium carbonate to pirssonite through this continuous dissolution and reprecipitation mechanism was also postulated by Bialik et al. [8]. However, more work is required to confirm the existence of either of the two mentioned mechanisms. The solubility of pirssonite in the system of $\mathrm{Na}_{2} \mathrm{CO}_{3}-\mathrm{CaCO}_{3}-\mathrm{H}_{2} \mathrm{O}$ was studied by Bury and Redd [9] from $25^{\circ} \mathrm{C}-95^{\circ} \mathrm{C}$. The effect of $\mathrm{NaOH}$ on pirssonite solubility at $95^{\circ} \mathrm{C}$ was investigated by Littman and Gaspari [10]. In this work, only four out of 12 scale samples characterized were found to consist of pirssonite; the remaining samples were composed of mostly $\mathrm{CaCO}_{3}$. The predominant presence of $\mathrm{CaCO}_{3}$ in the scale samples may be explained as follows.

Because the solubility of pirssonite is determined by temperature and $\mathrm{Na}_{2} \mathrm{CO}_{3}$ concentration of the green liquor [1,9], the solid $\mathrm{Na}_{2} \mathrm{CO}_{3}$ in the pirssonite scale will incongruently dissolve if the $\mathrm{Na}_{2} \mathrm{CO}_{3}$ concentration in the green liquor falls below the solubility limit of pirssonite. A common practice for preventing scaling in many kraft mills is to alternately switch green liquor and weak wash flows in the pipelines between the dissolving tank and the green liquor storage tank on a weekly basis. Therefore, it is possible that the pirssonite scale first forms during upset conditions (low temperature and high TTA). The formed pirssonite selectively leaches out

\section{ABOUT THE AUTHORS}

We chose this topic because there is a need to understand how hard scales form in order to devise a viable means to minimize their formation. This research was complementary to previous work by others, although it was more thorough in terms of analytical techniques used to characterize the samples.

The most difficult aspect of this work was to design and construct a laboratory apparatus that could simulate operating conditions in the causticizing plant of kraft pulp mills. We addressed that by conducting a thorough literature review and by putting all our expertise together. The most surprising finding was that the majority of samples consisted of calcite. We had expected that all scale samples would consist of pirssonite, but only one-third of them did and the rest consisted of calcite.

Mills may use this information to devise a viable means to minimize scale formation in their green liquor handling systems. The next steps will be to study how both pirssonite and calcite scales are formed, how the formation is affected by causticizing plant operations, and to develop a computer model

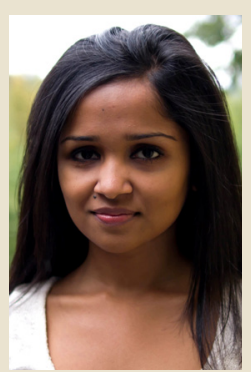

Zakhir

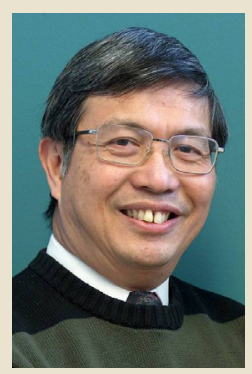

Tran

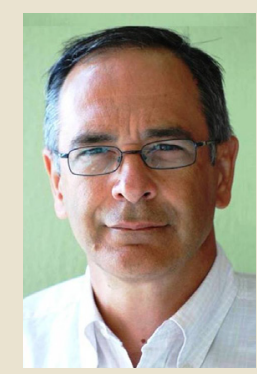

Papangelakis that can be used to predict whether scale can form under various operating conditions.

Zakhir is [need title], Tran is professor, and Papangelakis is [need title; info sheet provided had different authors - Bussman and Miikkulainen - please clarify] are with the Pulp \& Paper Centre and Department of Chemical Engineering and Applied Chemistry, University of Toronto, Toronto, ON, Canada. Email Tran at honghi. tran@utoronto.ca. 
its $\mathrm{Na}_{2} \mathrm{CO}_{3}$ part when the TTA is back to normal or during the weak wash switch, leaving the $\mathrm{CaCO}_{3}$ behind. The same concept may also be applied to the scale formation in the dissolving tank where localized and high TTA conditions prevail, leading to the precipitation of pirssonite followed by incongruent dissolution of $\mathrm{Na}_{2} \mathrm{CO}_{3}$ from the pirssonite at a lower TTA level.

\section{SUMMARY}

A systematic study was carried out to characterize 12 green liquor scale samples collected from $10 \mathrm{kraft}$ pulp mills. The results show that only four of the samples were pirssonite. The remaining eight were predominantly calcite, but the reasons are unknown. One possible explanation for that result is selective dissolution of $\mathrm{Na}_{2} \mathrm{CO}_{3}$ from the pirssonite scale during the time when the green liquor TTA was low, leaving the insoluble $\mathrm{CaCO}_{3}$ behind. $\mathbf{J}$

\section{ACKNOWLEDGEMENTS}

This work was conducted as part of the research program on Increasing Energy and Chemical Recovery Efficiency in the Kraft Process. The program is jointly supported by the Natural Sciences and Engineering Research Council of Canada (NSERC) and a consortium of the following companies: Andritz, Babcock \& Wilcox, Boise, Carter Holt Harvey, Celulose Nipo-Brasileira, Clyde-Bergemann, DMI Peace River Pulp, Fabria, International Paper, Irving Pulp \& Paper, Metso Power, MeadWestvaco, StoraEnso Research, and Tembec.

\section{LITERATURE CITED}

1. Frederick, W.J. Jr., Krishnan, R., and Ayers, R.J., Tappi J. 73(2): 135(1990).

2. Kosonen, J. and Salmenoja, K., TAPPI Eng. Conf., TAPPI PRESS, Atlanta, GA, USA, 1996, p. 793.

3. DeMartini, N. and Frederick, W.J. Jr., TAPPI Eng., Pulping Environ. Conf., TAPPI PRESS, Atlanta, 2008, [Author: Please indicate page or seesion number or indicate Conf. CDJ

4. Taylor, K. and McGuffie, B., Pulp Pap. Can. 108(2): 27-(2007).

5. Martins, F.M., Martins, J.M., Ferracin, L.C., et al., J. Hazard. Mater. 147(1-2): 610(2007).

6. Ulmgren, P., Rådeström, R., Edblad, M., et al., Int. Chem. Recovery Conf., vol. 2, TAPPI PRESS, Atlanta, 1998, p. 721.

7. Anthony, J.W., Bideaux, R.A., Bladh, K.W., et al., Eds., in Handbook of Minerology, Mineralogical Society of America, Chantilly, VA, USA. Available [Online] at http://www.handbookofmineralogy.org/ pdfs/pirssonite.pdf [May 2011].

8. Bialik, M., Wadsborn, R., Karlholm, I., et al., Int. Chem. Recovery Conf., vol. 1, TAPPI PRESS, Atlanta, 2010, p. 279.

9. Bury, C.R. and Redd, R., J. Chem. Soc. 0: 1160(1933).

10. Littman, F.E. and Gaspari, H.J., Ind. Eng. Chem. 48(3): 408(1956).

11. Johnson, D.R. and William, A.R., Am. Mineral. 58: 778(1973).

12. Fahey, J.J, and Mrose, M.E., U.S. Geol. Surv. Prof. Pap. 405: 1(1962). 